Tropical Journal of Pharmaceutical Research August 2012; 11 (4): 553-560

(C) Pharmacotherapy Group, Faculty of Pharmacy, University of Benin Benin City, 300001 Nigeria.

All rights reserved.

Available online at http://www.tjpr.org

Research Article

http://dx.doi.org/10.4314/tjpr.v11i4.5

\title{
Development and Evaluation of Ketoprofen Acrylic Transdermal Patches
}

\author{
Tanasait Ngawhirunpat*, Supinya Thipwichai, Praneet Opanasopit, \\ Theerasak Rojanarata and Suwannee Panomsuk ${ }^{1}$
}

Faculty of Pharmacy, Silpakorn University, Nakhon Pathom 73000, Thailand

\begin{abstract}
Purpose: To fabricate ketoprofen transdermal patches (KTPS) using an acrylic pressure-sensitive adhesive (PSA) polymer.

Methods: KTPs were prepared using solvent casting method. The influence of the amount of PSA, drug content, and terpenes as penetration enhancers on the characteristics of the patch, namely, thickness, W/A ratio, and adhesiveness and in vitro skin permeation, were investigated. Scanning electron microscope (SEM) and differential scanning calorimetry (DSC) studies were also performed on the patches. The physical and chemical stability of KTPs after storage at $40^{\circ} \mathrm{C}$, and $75 \% R H$ for 1 month was also evaluated.

Results: DSC thermograms demonstrate that the drug was dispersed molecularly in the polymer in all the formulations. Increase in PSA content increased the W/A ratio and adhesiveness of KTPS. Ketoprofen release from the transdermal patches followed the Higuchi diffusion model. Ketoprofen flux increased with increase in the ketoprofen content of the adhesive matrix. Inclusion of terpenes in the patch formulations significantly increased the permeation of ketoprofen through the skin, with enhancement ratio $(E R)$ ranging from 1.4 to 2.6 .

Conclusion: KTPs formulated with acrylic pressure-sensitive adhesive and incorporating terpenes as permeation enhancers demonstrated suitable characteristics for transdermal delivery of ketoprofen.
\end{abstract}

Keywords: Ketoprofen, Transdermal patch, Skin permeation, Acrylic matrix, Terpenes, Pressuresensitive adhesive. 


\section{INTRODUCTION}

Ketoprofen (KP) is a non-steroidal antiinflammatory and analgesic drug. KP causes gastrointestinal irritation when administered orally. One promising method to reduce this adverse effect is to deliver the drug through the skin. Various methods have been tried to enhance the delivery of KP through the skin including the use of liposomes, penetration enhancers and microemulsions [1-5].

Some ketoprofen transdermal patches (KTPs) have been developed by previous researchers. Okabe et al [6] reported that, among various polymer types, acrylic polymer resulted in the highest flux for KP. Adachi et al [7] found that a polymer matrix made up of styrene-isoprene-styrene (SIS) is an excellent material for the preparation of KTPs with good adhesiveness and skin permeation. Although various systems for the preparation of ketoprofen transdermal drug delivery devices have been reported in the literature [6-8], better systems that would result in improved patch stability and high skin permeation of KP are still required.

The objective of this work was to evaluate the effect of formulation factors, such polymer and drug content, and penetration enhancers, on the physicochemical properties and skin permeation of drug, KPT formulated with pressure-sensitive adhesive.

\section{EXPERIMENTAL}

\section{Materials}

Acrylic pressure-sensitive adhesive (Acrylax ${ }^{\circledR}$ ER-7306), siliconized paper and polyolefin backing membrane were gifts from Neoplast Co, Ltd, Patumthani, Thailand. Ketoprofen, indomethacin, and penetration enhancers (limonene, menthone and $\alpha$-pinene) were obtained from Sigma Chemicals, St Louis, $\mathrm{MO}$, USA. Commercial ketoprofen transdermal patch (Mohrus ${ }^{\circledR}$, Hitsamitsu Co, Ltd) was purchased from Tokyo, Japan. All other chemicals and solvents used were of analytical reagent grade.

\section{Preparation of ketoprofen transdermal patch (KTP)}

The composition of the KTPs is shown in Table 1. For each preparation, different proportions of ketoprofen alone or in combination with penetration enhancers (limonene, $\alpha$-pinene and menthone) were thoroughly mixed with acrylic PSA (solid content $45 \% \mathrm{w} / \mathrm{w}$ ) in a glass tube. The mixture was poured on a sheet $(10 \times 20 \mathrm{~cm})$ of polyolefin backing membrane that had been fixed onto a clean glass plate. The thickness of KTPs was controlled with a thinlayer chromatographic (TLC) plate scraper (Camag, Switzerland). The gap between the scraper and backing membrane was fixed at $0.5 \mathrm{~mm}$. The film was dried at $50{ }^{\circ} \mathrm{C}$ in a hot air oven for $1 \mathrm{~h}$ and then covered with siliconized release liner. The sheets of dried ketoprofen adhesive laminates were wrapped in aluminum foil and stored at $8{ }^{\circ} \mathrm{C}$ in a refrigerator.

\section{Measurement of patch thickness and weight/area ratio}

The thickness of the patch was measured using an electronic digital caliper (Ultracal IV

Table 1: Composition of the ketoprofen transdermal patches

\begin{tabular}{lcccccccc}
\hline Ingredient (g) & F1 & F2 & F3 & F4 & F5 & F6 & F7 & F8 \\
\hline Ketoprofen & 0.9 & 1.8 & 3.6 & 1.8 & 1.8 & 1.8 & 1.8 & 1.8 \\
Acrylic PSA & 100 & 100 & 100 & 50 & 200 & 100 & 100 & 100 \\
$\alpha$-pinene & - & - & - & - & - & 5 & - & - \\
Limonene & & & & & & - & 5 & - \\
Menthone & & & & & & & & 5 \\
\hline
\end{tabular}


Ted Pella, USA). The thickness of the adhesive matrix was determined as the difference in thickness between the patch with backing membrane and siliconized release liner together on the one hand, and the backing membrane and siliconized release liner, on the other. The weight/area (W/A) ratio of the patch was also determined. The patch $(1 \mathrm{~cm} \times 1 \mathrm{~cm})$ was cut and weighed accurately. The difference between the weight of ketoprofen patch and the weight of backing membrane divided by area provided the W/A ratio of the patch.

\section{Scanning electron microscopy studies}

(SEM)

The surface morphology of ketoprofen adhesive matrix film was characterized. by SEM. A sample of the patch was mounted on aluminum stubs using a two-sided adhesive tape, gold-coated in a vacuum evaporator, and photographed using a scanning electron microscope (Maxim MX 2000, Camtrad, England)

\section{Differential scanning calorimetry (DSC) studies}

Thermal analysis was performed with a Sapphire DSC (Perkin Elmer, MA, USA). The sample (ketoprofen powder, adhesive or patch) weighing about $2 \mathrm{mg}$ was placed in a crimped aluminum pan, sealed with a perforated lid and heated from -30 to $200{ }^{\circ} \mathrm{C}$ at a heating rate of $10{ }^{0} \mathrm{C} / \mathrm{min}$. The measurement was carried out under nitrogen atmosphere at a flow rate of $100 \mathrm{~mL} / \mathrm{min}$.

\section{Evaluation of adhesive property}

The adhesiveness of the transdermal patches was measured by a texture analyzer (TA.XT plus, NY, USA) equipped with rounded spherical ball probe.

Patches were cut into strips (2 cm diameter) and applied to an adherent plate made of stainless steel; it was smoothened with a $2 \mathrm{~kg}$ roller 3 times, and pulled from the substrate at an angle of $180^{\circ}$ at a rate of $5 \mathrm{~mm} / \mathrm{s}$. The measurement of the adhesiveness was carried out at $25 \pm 2{ }^{\circ} \mathrm{C}$.

\section{Stability studies}

The patches were stored at $40{ }^{\circ} \mathrm{C}$ and $75 \%$ relative humidity $(\mathrm{RH})$ for 30 days. Both physical and chemical stability of KP were evaluated. Chemical stability was determined by measuring KP content by HPLC (as described below) on days $0,7,15$, and 30 . Physical stability was assessed by examining for the presence of crystalline drug on the patch by SEM.

\section{Evaluation of in vitro skin permeation of the patches}

Shed snake skin of Naja khaothia was kindly donated by the Queen Saowabha Memorial Institute, Thai Red Cross Society, Bangkok, Thailand). It was used as a model membrane because of the similarities of its permeability to that of human skin [9]. It was obtained from 7 snakes. . Each skin can be divided into 10 - 12 pieces. The thickness of the skins ranged from $0.02-0.03 \mathrm{~mm}$, and was stored at $-10{ }^{0} \mathrm{C}$ prior to use. In vitro permeation experiments were performed using a Franz diffusion cell (MatTek Corporation, California, USA). The skin was mounted between the donor and receptor phases of the diffusion cell. The temperature of the receptor solution was maintained at 37 $\pm 0.5^{\circ} \mathrm{C}$ using a water jacket connected to a water bath. The receptor chamber had a volume $15.0 \mathrm{ml}$ volume with an effective diffusion area of $12.6 \mathrm{~cm}^{2}$. The patch was placed on a piece of the snake skin, which, in turn was placed on top of $\mathrm{pH} 7.4$ phosphate buffered saline (PBS) in the receptor chamber of diffusion cell. The receptor cell was stirred at $600 \mathrm{rpm}$ with a star-head Teflon $^{\circledR}$ magnetic bar (Nalge Nunc International Co., Ltd., Minnesota, USA) driven by a synchronous motor. At predetermined time intervals, $0.5 \mathrm{ml}$ of sample was taken from the receptor compartment and replaced with the same 
volume of fresh PBS. All experiments were carried out in triplicate. The samples were stored at $4{ }^{\circ} \mathrm{C}$ until analysis by HPLC. The cumulative amount of KP was plotted against time, and steady state flux was determined from the slope of the plots by linear regression analysis. The intercept on the $\mathrm{X}$ axis was determined as the lag time $\left(T_{L}, h\right)$. In order to evaluate effect of permeation enhancer, the enhancement ratio (ER) was determined as in Eq 1.

$\mathrm{ER}=\mathrm{Fe} / \mathrm{Fo}$

where $\mathrm{Fe}$ is the flux from the formulation with enhancer and Fo is the flux from the formulation without enhancer

\section{Determination of ketoprofen content}

A Perkin Elmer Series 2000 HPLC (Perkin Elmer, USA) was used to quantify the amount of KP. Chromatographic separation of KP was achieved using a symmetric $\mathrm{C} 18$ column (Perkin Elmer, Massachusetts, USA, particle size $=5 \mu \mathrm{m}$; column dimension $=4.6 \times 150$ $\mathrm{mm}$ ) operating at a flow rate of $1 \mathrm{ml} \mathrm{min}^{-1}$. The mobile phase comprised of $0.1 \% \mathrm{v} / \mathrm{v}$ phosphoric acid: methanol (25:75, v/v). Indomethacin was used as internal standard. The injection volume was $20 \mu \mathrm{l}$, and the UV detector was set at $254 \mathrm{~nm}$. All the sample solutions were filtered through a polytetrafluoroethylene (PTFE) filter (mean pore size $=0.45 \mu \mathrm{m}$ ) prior to injection. The calibration curve for KP was based on the range of 1 - $50 \mu \mathrm{g} \mathrm{ml}^{-1}$ with a correlation coefficient of 0.998 . Intra-day and inter-day percent relative standard deviation (\% RSD) was in the range $0.03-0.12 \%$.

\section{Statistical analysis}

All experimental measurements were carried out in triplicate. The results are expressed as mean \pm standard deviation (SD). Statistical significance of difference $(p<0.05)$ for steady state flux was examined using analysis of variance (ANOVA) with post-hoc test. SigmaStat software (version 3.5,
Richmond, CA, USA) was used for all analyses.

\section{RESULTS}

\section{Characteristics of KTPs}

The characteristics of the KTPs are shown in Table 2. All the KTPs were colourless, transparent, free of air bubbles, and had a smooth surfaces. SEM showed that there was no precipitation in the patches. Thickness and W/A ratio data for the ketoprofen patches showed low standard deviation (SD), indicating good reproducibility in their preparation. The thickness of the patches was in the range $102-104 \mu \mathrm{m}$, compared with $20 \square \mathrm{m}$ for the commercial patch, due to the difference in the composition and preparation methods of the test and commercial patch. W/A ratio in the range of $5-19 \mathrm{mg} / \mathrm{cm}^{2}$ was recorded for the test patches, while adhesiveness was 0.22 $0374 \mathrm{~N} / \mathrm{cm}$. Increase in KP content (F1 - F3) and incorporation of terpenes (as penetration enhancers) in the patches (F6 - F8) did not alter W/A ratio and adhesiveness of the KTPs. However, as the content of PSA in the patch increased, W/A ratio and adhesiveness of the KTPs significantly increased.

\section{Thermal properties}

The DSC thermograms of ketoprofen powder, PSA and ketoprofen transdermal patches are shown in Figure1. Ketoprofen powder showed an endothermic peak at about $96{ }^{\circ} \mathrm{C}$, but no similar peak was found for PSA and ketoprofen transdermal patch (F1, F2 and F3).

\section{Stability of KTPs.}

Chemical stability data (expressed as percent $\mathrm{KP}$ remaining in the patch) of the KTPs are presented in Fig 2. KP remaining after storage at $40{ }^{\circ} \mathrm{C} / 75 \% \mathrm{RH}$ for 30 days was in the range $90-95 \%$. There was no 
Table 2: Characteristics of KP transdermal patches

\begin{tabular}{|c|c|c|c|c|c|c|c|}
\hline \multirow{2}{*}{ Formulation } & \multicolumn{2}{|c|}{ Ketoprofen content } & \multirow{2}{*}{$\begin{array}{l}\text { Thickness } \\
(\mu \mathrm{m})\end{array}$} & \multirow{2}{*}{$\begin{array}{l}\text { W/A } \\
\text { ratio } \\
\left(\mathrm{mg} / \mathrm{cm}^{2}\right)\end{array}$} & \multirow{2}{*}{$\begin{array}{l}\text { Adhesiveness } \\
(\mathrm{N} / \mathrm{cm})\end{array}$} & \multirow{2}{*}{$\begin{array}{l}\text { Flux } \\
\left(\mu \mathrm{g} / \mathrm{cm}^{2} / \mathrm{h}^{1 / 2}\right)\end{array}$} & \multirow{2}{*}{$\begin{array}{l}\text { Lag time } \\
\text { (h) }\end{array}$} \\
\hline & $\left(\mathrm{mg} / \mathrm{cm}^{2}\right)$ & $\% w / w$ & & & & & \\
\hline F1 & $0.14 \pm 0.02$ & $1.43 \pm 0.01$ & $102.6 \pm 4.3$ & $9.9 \pm 0.5$ & $0.485 \pm 0.075$ & $0.66 \pm 0.03$ & $0.71 \pm 0.03$ \\
\hline $\mathrm{F} 2$ & $0.29 \pm 0.02$ & $2.84 \pm 0.01$ & $102.6 \pm 4.3$ & $10.2 \pm 0.2$ & $0.462 \pm 0.095$ & $1.33 \pm 0.12$ & $0.67 \pm 0.02$ \\
\hline F3 & $0.45 \pm 0.03$ & $4.41 \pm 0.04$ & $102.6 \pm 4.3$ & $10.1 \pm 0.3$ & $0.448 \pm 0.104$ & $2.62 \pm 0.21$ & $0.74 \pm 0.06$ \\
\hline F4 & $0.29 \pm 0.04$ & $2.84 \pm 0.02$ & $102.6 \pm 4.3$ & $5.1 \pm 0.3$ & $0.228 \pm 0.081$ & $0.74 \pm 0.07$ & $0.52 \pm 0.04$ \\
\hline F5 & $0.29 \pm 0.04$ & $2.84 \pm 0.01$ & $102.6 \pm 4.3$ & $19.2 \pm 0.1$ & $0.741 \pm 0.079$ & $2.23 \pm 0.18$ & $0.61 \pm 0.03$ \\
\hline F6 & $0.30 \pm 0.02$ & $2.85 \pm 0.02$ & $102.6 \pm 4.3$ & $10.4 \pm 0.9$ & $0.426 \pm 0.076$ & $3.43 \pm 0.31$ & $0.53 \pm 0.03$ \\
\hline F7 & $0.29 \pm 0.02$ & $2.85 \pm 0.02$ & $102.6 \pm 4.3$ & $10.2 \pm 0.7$ & $0.423 \pm 0.079$ & $2.51 \pm 0.14$ & $0.61 \pm 0.02$ \\
\hline F8 & $0.29 \pm 0.01$ & $2.85 \pm 0.01$ & $102.6 \pm 4.3$ & $10.1 \pm 0.8$ & $0.428 \pm 0.090$ & $1.84 \pm 0.11$ & $0.57 \pm 0.01$ \\
\hline $\begin{array}{l}\text { Commercial } \\
\text { product }\end{array}$ & $0.29 \pm 0.01$ & $2.85 \pm 0.05$ & $20.3 \pm 1.0$ & $10.3 \pm 0.6$ & $0.312 \pm 0.009$ & $1.42 \pm 0.13$ & $0.71 \pm 0.02$ \\
\hline
\end{tabular}

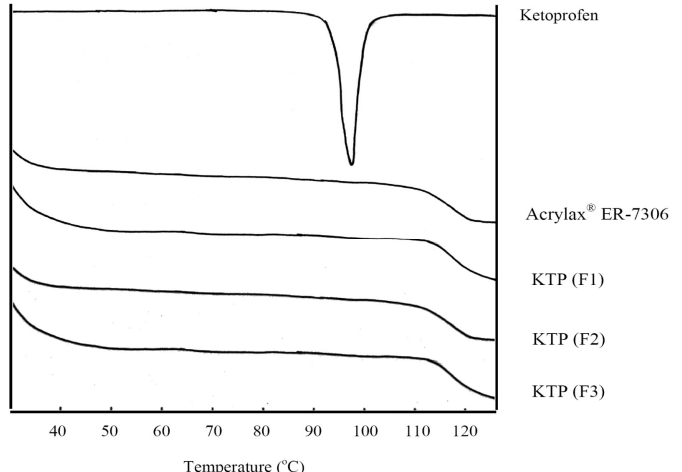

Figure 1: DSC thermogram of KTP and its major components

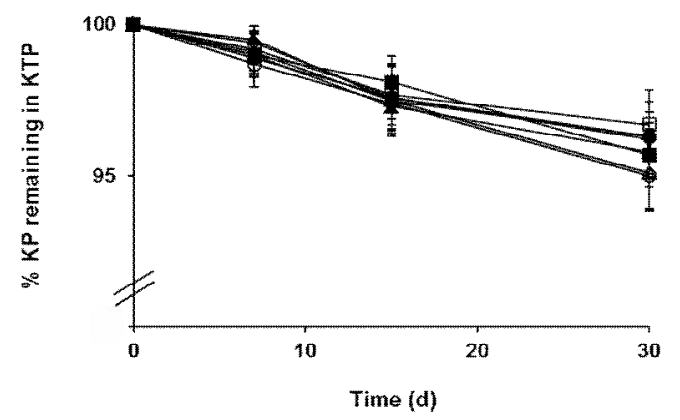

Figure 2: $\mathrm{KP}$ content (mean $\pm \mathrm{SD}, \mathrm{n}=3$ ) of patches after storage at $40^{\circ} \mathrm{C} / 75 \% \mathrm{RH}$ over a 30-day period.

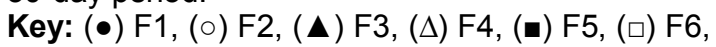
$(\diamond) F 7$, and $(\diamond) F 8$.

\section{In vitro skin permeation of KTPs}

The snake skin permeation profile of ketoprofen from different formulations of ketoprofen transdermal patches is presented in Figure 3. The permeation parameters (flux and lag time) of ketoprofen are summarized in Table 2. The plot of the amount of ketoprofen that have permeated the skin layer and square root of time are linear with a correlation coefficient $\left(R^{2}>0.98\right)$, and a short lag time. Ketoprofen flux increased when ketoprofen content of the patch increased from $0.14(F 1)$ through $0.29 \mathrm{mg} / \mathrm{cm}^{2}(\mathrm{~F} 2)$, to $0.45 \mathrm{mg} / \mathrm{cm}^{2}$ (F3) (Fig 3a), showing a correlation coefficient $\left(R^{2}\right)>0.99$. However, ketoprofen flux decreased significantly $(p<$ 0.05), when PSA content of the patch increased (Fig. 3b). There was no significant difference between the KP flux of F2 and the commercial (reference) patch (Fig 3c, Table 2 ). Incorporation of penetration enhancers ( $\alpha$ pinene, limonene or menthone) in the patches increased KP flux (Figure 3c, Table 2). The presence of terpene enhancers produced a 1.4- to 2.6-fold flux increase (F6 F8) over the patch without any terpene (F2). Among the terpenes, $\alpha$-pinene showed the highest ER for the patches; ER was in the rank order: $\alpha$-pinene >limonene >menthone. The lag time of the KTPs (F1 - F8) was not significantly different $(p>0.05)$. 

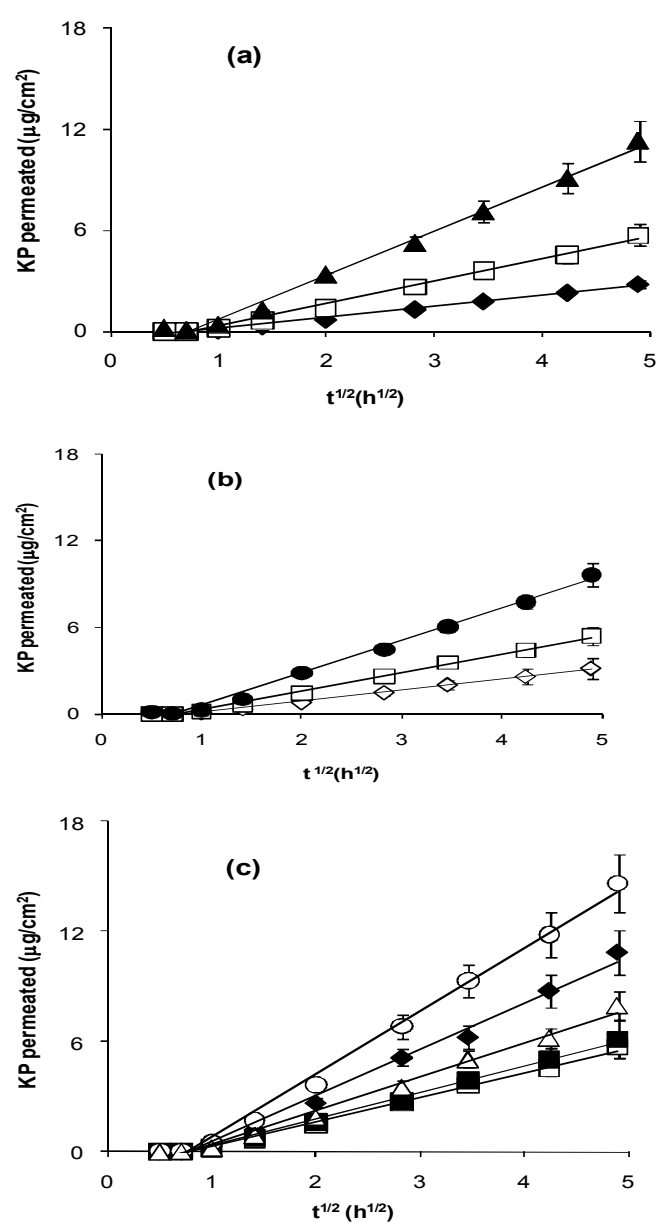

Figure 3: Permeation of ketoprofen from KTPs: (a)

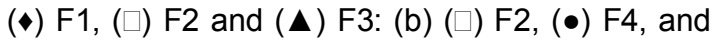
$(\diamond) \mathrm{F}$; ; and (c) ( $\square$ ) F2, ( $\square$ ) commercial (reference) patch, (॰) F6, ( $\bullet) F 7$, and $(\Delta)$ F8 through shed snake skin (mean $\pm S D, n=3$ ).

\section{DISCUSSION}

KTPs using acrylic pressure sensitive adhesive as matrix and terpene as skin penetration enhancers have been successfully developed in the present study. Acrylates are saturated polymers and are resistant to oxidation, and therefore, does not undergo colour change upon exposure to sunlight [10]. of the developed KTPs demonstrated suitable characteristics they were colourless, transparent, free of air bubbles, smooth and without evident precipitation of drug. Moreover, good physical and chemical stability was obtained.

Increase in PSA content enhanced the adhesiveness of the patch as a result of the higher cohesive force between the polymers. The DSC endotherm indicated a transition for $\mathrm{KP}$ between 90 to $100{ }^{\circ} \mathrm{C}$, due probably to solid to liquid transition since the melting point of KP is $94^{\circ} \mathrm{C}$. Since pure PSA and the PSA incorporated with KP did not show any endothermic peak in this region, it can be said that there was no interaction between the drug and the polymer.

The high correlation coefficient between ketoprofen permeation and square root of time indicates that the patch-skin system formed a single homogeneous polymeric film [11]. Ketoprofen flux increased when ketoprofen content in the patches was increased. These results are similar to those obtained for nicotine acrylic patch [11,12]. The higher the ketoprofen content of the patch, the higher the diffusion activity of the drug; furthermore, the higher drug content reduces the relative amount polymer matrix, thus lowering the diffusional barrier to the drug. Ketoprofen flux decreased when PSA content increased due to the fact that increase in the latter also increased the diffusion barrier of the polymer matrix to KP permeation [13].

The possible mechanism of terpene enhancement of KP permeation may be disruption in skin morphology as a result of the lipid fluidizing activity of terpenes [14]. Terpenes are known to extract lipids from stratum corneum [15], resulting in disorder of lipid domains. Moreover, terpenes also facilitate drug diffusion by increasing partitioning of the drugs into the stratum corneum [16]. The difference in the permeation enhancement ratios of the terpenes may be linked to differences in their molecular weights and boiling points. Thus, $\alpha$-pinene and limonene exhibited higher penetration enhancement than menthone 
because of their lower boiling points and molecular weights. Low boiling point of a terpene indicates there is weak cohesiveness or self-association of the molecules [17], and therefore they are likely to more easily associate or interact with the lipid components of the stratum corneum and alter hence alter its barrier property. Our results were consistent with those of Narishetty \& Panchagnula [18] who reported that for hydrophobic drugs such as indomethacin, lipophilic terpenes, such as limonene, were effective enhancers.

The lag time of the KTPs formulations was not significantly different with respect to the terpene type. This finding is in agreement with that of of Maghraby [19]. The lag time is a permeation parameter that depends mainly on drug diffusivity through skin. However, it does not depend directly on the drug release. The absence of a significant lag time confirms that skin permeation of $\mathrm{KP}$ is not dependent on drug release.

\section{CONCLUSION}

KTPs prepared acrylic PSA were successfully developed. The patches showed good physical and chemical stability as well as satisfactory permeation characteristics. However, in vivo studies are required to determine the patch's actual suitability for transdermal delivery of ketoprofen

\section{ACKNOWLEDGEMENT}

The authors wish to thank The Thailand Research Funds for financial support through Grant no. RSA 5280001.

\section{REFERENCES}

1. Podlogar F, Rogač MB, Gašperlin M. The effect of internal structure of selected water-Tween $40^{\circledR}$ Imwitor $308^{\circledR}$-IPM microemulsions on ketoprofen release. Int J Pharm 2005; 301: 6877.

2. Rhee YS, Choi JG, Park ES, Chi SC. Transdermal delivery of ketoprofen using microemulsions. Int J Pharm 2001; 228: 161-170.
3. Zhao L, Fang L, Xu Y, Liu S, He Z, Zhao Y. Transdermal delivery of penetrants with differing lipophilicities using O-acylmenthol derivatives as penetration enhancers. Eur $J$ Pharm Biopharm 2008; 69: 199-213.

4. Shinkai N, Korenaga K, Mizu H, Yamauchi H. Intraarticular penetration of ketoprofen and analgesic effects after topical patch application in rats. J Control Release 2008, 131: 107-112.

5. Sakeena MH, Elrashid SM, Muthanna FA, Ghassan ZA, Kanakal MM, Laila L, Munavvar AS, Azmin $M N$. Effect of limonene on permeation enhancement of ketoprofen in palm oil esters nanoemulsion. J Oleo Sci 2010; 59(7): 395400.

6. Okabe H, Takayama K, Nagai T. Percutaneous absorption of ketoprofen from acrylic gel patches containing d-limonene and ethanol as absorption enhancers. Chem Pharm Bull 1992; 40: 1906-1910.

7. Adachi H, loppolo F, Paoloni M, Santilli V. Physical characteristics, pharmacological properties and clinical efficacy of the ketoprofen patch: a new patch formulation. Eur Rev Med Pharmacol Sci 2011; 15(7): 823-830.

8. Cheng $Y$, Man N, Xu T, Fu R, Wang X, Wang $X$, Wen $L$. Transdermal delivery of nonsteroidal anti-inflammatory drugs mediated by polyamidoamine (PAMAM) dendrimers. J Pharm Sci 2007; 96(3): 595-602.

9. Ngawhirunpat $T$, Opanasopit $P$, Rojanarata $T$, Panomsuk S, Chanchome L. Evaluation of simultaneous permeation and metabolism of methyl nicotinate in human, snake, and shed snake skin. Pharm Dev Tech 2008; 13(1): 7583.

10. Autchter G, Aydin O, Satas D. Acrylic adhesives. In: Satas $D(E d)$. Handbook of pressure sensitive adhesive technology. $3^{\text {rd }}$ edn. Rhode Island: Satas and Associates Warwick; 1989. pp 444447.

11. Pongjanyakul T, Prakongpan S, Priprem A. Acrylic matrix type nicotine transdermal patches: in vitro evaluations and batch-to-batch uniformity. Drug Dev Ind Pharm 2003; 29(8): 843-853.

12. Pongjanyakul $T$, Prakongpan $S$, Panomsuk $S$, Puttipipatkhachorn S, Priprem A. Shed king cobra and cobra skins as model membranes for in-vitro nicotine permeation studies. J Pharm Pharmacol 2002; 54(10): 1345-1350.

13. Luppi B, Bigucci F, Baldini M, Abruzzo A, Cerchiara $T$, Corace G, Zecchi V Hydroxypropyl methylcellulose films for prolonged delivery of the antipsychotic drug, chlorpromazine. $J$ Pharm Pharmacol 2010; 62(3): 305-309.

14. William AC, Barry BW. Terpenes and the lipidprotein partitioning theory of skin penetration enhancement. Pharm Res 1991; 8(1): 17-24.

15. Ogiso T, Paku T, Iwaki M, Tanino T. Percutaneous penetration of fluorescein isothiocyanatedextrans and the mechanism for enhancement effect of enhancers on the intercellular 
Ngawhirunpat et al

penetration. Biol Pharm Bull 1995; 18(11): 1566-1571.

16. Zhao $K$, Singh J. Mechanisms of in vitro percutaneous absorption enhancement of tamoxifen by enhancers. J Pharm Sci 2000; 89(6): 771-780.

17. Vaddi HK. Terpenes in propylene glycol as skinpenetration enhancer: permeation and partition of haloperidol, Fourier transform infrared spectroscopy and differential scanning calorimetry. J Pharm Sci 2002; 91: 1639 1651.

18. Narishetty ST, Panchagnula, R. Transdermal delivery of zidovudine: Effect of terpenes and their mechanism of action. J Control Release 2004; 95(3): 367-379

19. Maghraby GM. Transdermal delivery of hydrocortisone from eucalyptus oil microemulsion: Effects of cosurfactants. Int $J$ Pharm 2008; 355: 285-292. 